\title{
Fundamental Study of Low-NOx Combustion Fly Ash Utilization
}

\author{
Semi-Annual Report \\ October 1, 1996 - March 31, 1997
}

\author{
By \\ R. H. Hurt; E. M. Suuberg; Y. M. Gao; W. D. Lilly \\ I Küloats; K. Smith; N. Sabanegh
}

Work Performed Under Contract No.: DE-FG22-96PC96213

\author{
For \\ U.S. Department of Energy \\ Office of Fossil Energy \\ Federal Energy Technology Center \\ P.O. Box 880 \\ Morgantown, West Virginia 26507-0880
}

By

Division of Engineering

Brown University

Providence, Rhode Island 02912 


\section{Disclaimer}

This report was prepared as an account of work sponsored by an agency of the United States Government. Neither the United States Government nor any agency thereof, nor any of their employees, makes any warranty, express or implied, or assumes any legal liability or responsibility for the accuracy, completeness, or usefulness of any information, apparatus, product, or process disclosed, or represents that its use would not infringe privately owned rights. Reference herein to any specific commercial product, process, or service by trade

name, trademark, manufacturer, or otherwise does not necessarily constitute or imply its endorsement, recommendation, or favoring by the United States Government or any agency thereof. The views and opinions of authors expressed herein do not necessarily state or reflect those of the United States Government or any agency thereof. 


\title{
FUNDAMENTAL STUDY OF LOW-NOx COMBUSTION FLY ASH UTILIZATION
}

\author{
FIRST SEMI-ANNUAL REPORT
}

REPORTING PERIOD: OCTOBER 1, 1996 - MARCH 31, 1997

R.H. HURT AND E.M. SUUBERG (PRINCIPAL INVESTIGATORS) Y.M. GAO AND W.D. LILLY (STAFF)

I. KÜLAOTS (Ph.D. CANDIDATE)

K. SMITH AND N. SABANEGH (UNDERGRADUATE ASSISTANTS)

\author{
REPORT ISSUED: MAY, 1997 \\ DOE AWARD NUMBER: DE-FG22-96PC9621-013 \\ ISSUING ORGANIZATION: DIVISION OF ENGINEERING \\ BROWN UNIVERSITY \\ PROVIDENCE, RI 02912 \\ REPORT PREPARED BY: T.M. SUUBERG \\ TEL. (401) 863-1420 \\ FAX (401) 863-1157
}

"US/DOE Patent Clearance is not required prior to the publication of this document" 


\begin{abstract}
This study is principally concerned with characterizing the organic part of coal combustion fly ashes. High carbon fly ashes are becoming more common as by-products of low-NOx combustion technology, and there is need to learn more about this fraction of the fly ash. The project team consists of two universities, Brown and Princeton, and an electrical utility, New England Power. A sample suite of over forty fly ashes has been gathered from utilities across the United States, and includes ashes from a coals ranging in rank from bituminous to lignite. The characterizations of these ashes include standard tests (LOI, Foam Index), as well as more detailed characterizations of their surface areas, porosity, extractability and adsorption behavior. The ultimate goal is, by better characterizing the material, to enable broadening the range of applications for coal fly ash re-use beyond the current main market as a pozzolanic agent for concretes. The potential for high carboncontent fly ashes to substitute for activated carbons is receiving particular attention. The work performed to date has already revealed how very different the surfaces of different ashes produced by the same utility can be, with respect to polarity of the residual carbon. This can help explain the large variations in acceptability of these ashes as concrete additives.
\end{abstract}




\section{Table of Contents}

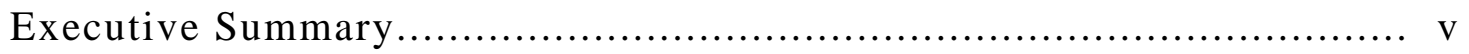

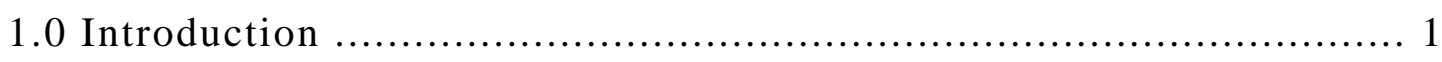

1.1 Project Description ............................................ 2

2.0 Progress During This Reporting Period..........................................6

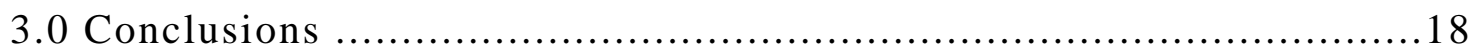

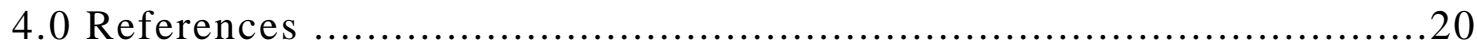

Appendix A - LOI test procedures........................................... 21

Appendix B -Foam Index Test Procedure........................................22

Appendix C -Microcalorimetry Equipment and Procedures ...........................23 


\title{
EXECUTIVE SUMMARY
}

\section{FUNDAMENTAL STUDY OF LOW-NOx COMBUSTION FLY ASH UTILIZATION (DE-FG22-96PC96213)}

\begin{abstract}
Background
The Nation faces a serious question concerning what to do with fly ash from coal-fired power stations. Only about $14 \%$ is presently utilized in cement and concrete products, and this is by far the largest single re-use market for this material. Most of the remainder is landfilled and thus there is clear economic incentive for utilities to seek new opportunities for utilization. This project is concerned with better characterization of the fly ash, and identification of potential new uses of the ash. It is the "organic" portion of the ash, the unburned carbon, which may be the key to success in many new utilization schemes. The unburned carbon content has been significantly increased and altered by the introduction of new NOx control technology. The increased levels of carbon, and the different nature of the carbon, may offer new opportunities for ash re-utilization at the same time as these characteristics cause problems in concrete-based reuse.
\end{abstract}

\section{Project Overview}

This project involves a collaborative effort between two universities (Brown and Princeton) and an electric utility (New England Power). The goal is to provide a more basic understanding of the nature of the organic fractions of fly ash. Four specific tasks have been defined:

1. Characterization of the physical and chemical nature of ash organics. This task involves a) acquiring a suite of fly ash samples from utilities throughout the country, b) characterizing this set of samples, or a subset, with respect to organic (carbon and extractables) content, surface area and porosity characteristics. Also as part of this task, the oxidation reactivity of the unburned carbon is being measured. The results will be related to the results of the standard LOI test, and to the performance of the fly ashes with respect to the tests in the tasks listed below.

2. Development of new screening tests to evaluate the samples with respect to various applications. This includes further development of a test for fine carbon content and identification of a simple alternative to the foam index test, both of which can serve as measures of suitability of the ash in concrete applications.

3. Characterization of the adsorption behavior of selected fly ashes relative to various organic and inorganic adsorbates.

4. Examination of the technical suitability of high-carbon coal fly ash as a low-cost alternative to activated carbon in adsorption applications.

\section{Progress to Date}

A suite of approximately 40 samples, representative of utility practice across the country, has been assembled, and is being characterized as described in task 1 above. Tests of the adsorption behavior of the fly ashes have also begun, with an examination of the polar characteristics of their surfaces. This relates to task 3 , but this work has additionally provided new insights into what determines whether a particular ash is suitable for concrete applications. The role of porosity in determining the adsorptive behavior of fly ashes has also been examined. It is apparent that the carbons of different fly ash samples offer differing levels of accessibility to potential organic adsorbates. 


\subsection{INTRODUCTION}

The Nation's electric utilities produce an enormous amount of coal fly ash - recently about 48 million tons per year ${ }^{1}$. These utilities have long preferred recycling or reuse of the ash to landfill or pond disposal, but increasing landfill costs, liability concerns and other industry developments have shifted what was a mild preference for recycling to an imperative at many companies. At the present time, concrete products represent the major market for the ash, and consume about $1 / 6$ of the total produced ${ }^{1}$. Most of the remainder is presently landfilled. Many new market opportunities have been explored ${ }^{2}$, including lightweight aggregate, flowable fill, cement kiln feedstock, structural fill, alternate fuels, filtration media, ladle topping, fertilizer, casting sands and soil additives. To this list must be added sorbent applications, particularly for high carbon ashes from low- $\mathrm{NO}_{\mathbf{X}}$ combustion.

The widespread application of low- $\mathrm{NO}_{\mathrm{X}}$ combustion technologies has recently increased the carbon levels in fly ash at many utilities. In many instances, this has rendered

the fly ash unsuitable for sale to the concrete industry ${ }^{3}$. Even in situations in which the carbon contents are within ASTM specifications, problems have still been reported with ashes from low- $\mathrm{NO}_{\mathrm{X}}$ combustion systems. Recent work at Brown University and New England Power has suggested that the problem might be related to changes in the form and sorptive properties of the carbon 4,5 . One of the goals of this project is development of a clearer understanding of what governs the performance of carbon-containing ash in concrete-type applications.

Unfortunately, most of the fundamental research on ash characterization has focused on the inorganic (majority) component of fly ash - its particle size, morphology, and chemical composition. It is the organic portion of the ash, consisting mainly of carbon, that could hold the key to success or failure in many new utilization schemes. It is the clearly significant role that carbon plays in concrete applications that has motivated the 
development of a variety of processes for carbon separation or removal from ash. These include processes based upon electrostatic separation, froth flotation, and carbon burnout outside the utility boiler. In the case of the separation schemes, streams considerably enriched in carbon (to tens of percent by mass) could become available. This may further expand the potential markets for application of the ash-derived materials to include some currently dominated by activated carbons, particularly powdered activated carbons.

In this project, Brown and Princeton Universities are teamed with New England Power to undertake a broad-based scientific investigation of the form, sorptive properties and behavior of the organic material in ash samples in order to help identify new commercial opportunities. The objectives of the research are to 1) thoroughly characterize the organic matter in ash with respect to form (including char-derived carbon, soot, and extractables), structure and surface properties, 2) examine the sorptive properties of ashes in technologically significant situations, and 3) to define new applications opportunities.

\subsection{PROJECT DESCRIPTION}

The project has been divided into four basic tasks, as outlined below. These tasks will be carried out by teams consisting of researchers from Brown, Princeton and New England Power. Project management is the responsibility of the team at Brown.

\section{Task 1- Physical and Chemical Characterization of Ash Organics. Sample acquisition}

The first part of this task involves acquiring a suite of fly ash samples from utilities throughout the country. These are being selected on the basis of recommendations from utilities and ash brokers, to be representative of "normal" practice as well as unusual situations. It is anticipated that the set of samples will ultimately contain over 40 wellcharacterized commercial fly ash samples. Several extensively studied fly ash samples have 
been provided by New England Power. These have the advantage of having been prepared under relatively well-defined conditions.

\section{Physical Characterization}

All samples will be characterized in-house at Brown with respect to organics content, carbon form and morphology, surface area, and porosity. The main characterization of organics content involves the standard loss-on-ignition (LOI) test. The results of this test are being re-evaluated in ancillary burnout tests. Selected samples will be analyzed for extractables content by the team at Princeton. As part of another program at Brown, this set of data will be supplemented by the results of the "Foam Index" test, which is one of the key assays for suitability in concrete applications. This test will be discussed further below.

\section{Task 2- Analytical Technique Development}

There is a strong incentive to develop new screening tests to determine the suitability of coal fly ashes for concrete applications. Fly ashes sold for concrete use are currently classified according to several tests. There are categories based upon inorganic content, which are strongly related to the type of coal from which they are derived -Type F ash is derived from anthracite, bituminous and certain sub-bituminous coals and Type C ash usually comes from combustion of lignites and sub-bituminous coals. There are also criteria for the organic content. To qualify as a concrete additive, a fly ash must as a minimum meet the ASTM C618 standards, including one prescribing that the ash not exhibit more than 6 wt.\% loss on ignition (LOI). These standards are, however, not generally sufficient to ensure good performance, and have been superseded by even more stringent local regulations on LOI.

In addition, samples of fly ash must typically be tested for performance with respect to specific key additives in the concrete, the so-called Air Entraining Admixtures (AEAs). 
The AEAs are used to ensure that the final concrete will contain sufficient numbers of air bubbles, of the proper size, in order to impart good workability and freeze-thaw resistance to the concrete. The test used for this purpose is the "Foam Index" test, in which the required amount of AEA is measured in what is essentially a titration test, the endpoint of which is determined by the stability of the foam created in a water solution of the AEA, which is a surfactant (see ref. 4-6). A deficiency of the Foam Index test is the fact that it gives no insight into why a particular ash may require an unacceptably high level of AEA. There are also sometimes problems with the dynamics of the test - there have been reports of samples that tested well at short times that have gone "flat" at the jobsite, due to slow loss of AEA.

The recent work at Brown has strongly suggested that the unburned carbon is acting an adsorbent relative to the (organic) AEA surfactants. This work indicated that surface area of the unburned carbon in the fly ash is a key criterion in determining AEA requirements in the Foam Index test 4,5 . If there are a variety of different carbons in a single fly ash, then a LOI criterion for concrete performance could clearly be insufficient. Indeed, soot has recently been identified (using electron microscopy) in some samples from low- $\mathrm{NO}_{\mathrm{X}}$ firing. Soot particles would offer a much different surface area per unit mass of carbon than does unburned char. This has led to proposal of a new test to characterize the nature of the carbons in fly ash based upon fine particle content of the $\mathrm{ash}^{4}$. This new test is referred to as the Gao Fine Particle test.

It is the purpose of this task to develop this new fine particle test further, in order to determine whether it can be a useful supplement to the other tests already in use. The Gao fine particle test has shown some promise as a simple indicator of the quantify of carbonaceous submicron particulate matter, but is a single point measurement with an arbitrary (and unknown) size threshold. We will attempt to optimize, quantify, and validate the Gao test through the use of multi-point centrifugation tests with microscopic verification of particle sizes. The ultimate goal of this work and the associated microscopy and 
sorption studies is to develop a procedure that can be used to assess the general importance of soot as a component in low- $\mathrm{NO}_{\mathrm{x}}$ ash samples - how prevalent are soot-containing samples from low- $\mathrm{NO}_{\mathrm{x}}$ systems, what soot concentrations are present, and what is this soot's activity toward the adsorbates of interest? Finally, some development work will be undertaken to define a more fundamental sorption test, which will be more readily interpretable and more reproducible than the industry-standard Foam Index test.

\section{Task 3- Adsorption Experiments Involving Strategic Compounds}

This work, to be conducted at Brown, will investigate the sorptive behavior of ash organics in a fundamental way, and the results will allow prediction of ash interactions with aqueous wastes, organic wastes, air toxic vapors, and air entraining admixtures in concrete. Testing will be performed in both water and air, to evaluate potential for purification applications in both media. An important characteristic of the ash carbons will be whether they have hydrophilic or hydrophobic surfaces. This will be determined both by measuring water vapor sorption isotherms, as well as by using new adsorption calorimetry methods 7 (see below).

The adsorptive capacity of the surface for non-polar organic vapors will be determined by use of propane or butane, employing a recently described temperature

programmed methodology 8 . Similarly, a model aromatic adsorbate, such as benzene or toluene, a basic adsorbate, such as ammonia or propyl amine, and a chlorinated hydrocarbon such as carbon tetrachloride, will be examined, with respect to vapor sorption capacity and kinetics. Benzene is particularly significant as the most easily leachable adsorbate found in municipal gas plant wastes. Such sites have been considered by new England Power as potential target sites for remediation.

The suitability for water purification will be examined by experiments in which various components are partitioned onto the carbon from water. The experiments already under way with AEA compounds will provide some guidance as to selection of candidate 
ashes. The so-called "bottle point" method ${ }^{9}$ can be used to examine the uptake of water contaminants such as p-nitrophenol or phenol, which can serve as reasonable (and widely used) benchmarks of performance.

\section{Specialized research in support of new markets}

The work outlined in Tasks 1 and 2 will provide the basic database needed to support the development of a wide variety of new ash applications. We anticipate nevertheless that additional research will be carried out to provide accurate data for new applications that continue to arise in this fast-moving research area. New England Power is planning a comprehensive market survey for their high-carbon products that is likely to suggest additional experimentation. As an example, specific experiments may be included to directly assess the potential of high carbon as a low-cost additive for $\mathrm{Hg}$ vapor capture by duct injection in municipal solid waste combustors.

\section{Task 4- Comparative evaluation against commercial activated carbons.}

In most of the applications considered for high-carbon ash, it competes directly with commercial activated carbons - materials that offer better performance but at a much higher cost. It is critical for the economic evaluations to have direct comparisons between the new materials (fly ash streams) and accepted commercial products. As a final task, we will therefore compile a summary of relevant information on commercial carbons, and to critically assess the performance of the fly ash streams against these competing materials.

\subsection{PROGRESS DURING THIS REPORTING PERIOD}

A kickoff meeting of all main project participants was held on October 31 of 1996, at the Brayton Point Power Station of New England Power. Participants included the coprincipal investigators from Brown, Professors Hurt and Suuberg, the principal 
investigator from the Princeton group, Professor Wornat, and Mr. Peter Calvert of New England Power. The discussion centered on defining areas of responsibility, and the need to build up a reliable set of samples for study.

The decision has been made to expand the set of samples beyond those that New England Power can supply from its own operations, as it was felt that broadening the sample base was important to drawing sound fundamental conclusions. Since the problems caused by variations in unburned carbon are experienced nationwide, but the nature of the ashes from different utilities are quite different, it would be dangerous to focus the study too narrowly. The interests and experience of New England Power will, however, continue to be important in guiding the search for viable commercial applications.

\section{Establishment of the sample bank}

The actual experimental work during this quarter focused upon Tasks 1 and 3. In the case of Task 1, assembly of a reliable, representative sample set was the first step. The current status of this effort is given in Table 1, which shows the samples that have been currently entered into the set. It is likely that more will be entered. Since the samples were obtained from various commercial sources, and there might be significant variability in composition during normal operations, all samples were rechecked for LOI using the standard ASTM method (Standard No. D3174-82). Some discrepancies, relative to the supplied LOI values, were encountered, though there was generally good agreement with the values supplied with the samples. All samples were subjected to replicate LOI determinations. It was noted that when reported LOI values were less than $1 \%$, large uncertainties were possible. Efforts have been made in these cases to check the standard LOI method against measurements performed in a thermogravimetric analyzer (TGA). The procedures are outlined in Appendix A. These tests indicated a complex pattern of mass loss with time, and work on this point continues. It is well known that reactions involving 


\section{Table 1. Fly Ash Sample Bank}

\begin{tabular}{|c|c|c|}
\hline $\begin{array}{l}\text { Sample } \\
\text { No. }\end{array}$ & $\begin{array}{c}\text { LOI } \\
(\operatorname{mass} \%)\end{array}$ & Remarks \\
\hline FA1 & 6.5 & NEP - Brayton pt., Unit \#3, \#3E, unprocessed, problem ash \\
\hline FA2 & & NEP - Brayton pt., Unit \#3, from problem ash, STI processed \\
\hline FA3 & 14.6 & NEP - Brayton Point, Silo \#2, \#2D+E unprocessed, good ash \\
\hline FA4 & & NEP - Brayton pt., Unit \#2, unprocessed \\
\hline FA5 & 1.9 & $\begin{array}{l}\text { NEP - Brayton pt., Unit \#3, pre low-NOx conversion, good } \\
\text { ash, CPI=0.14 }\end{array}$ \\
\hline FA6 & 3.4 & NEP - Brayton pt., poor air entrainment (Tresca 5252) \\
\hline FA7 & 2.6 & $\begin{array}{l}\text { NEP - Brayton pt., (BPP 50612-260,T24), problem ash, from } \\
\text { STI }\end{array}$ \\
\hline FA8 & 3.8 & $\begin{array}{l}\text { NEP - Brayton pt., (BPP 50612-261,T34), poor air } \\
\text { entrainment, from STI, CPI=0.74 }\end{array}$ \\
\hline FA9 & 65.3 & NEP - Brayton pt., black in color, from STI \\
\hline FA10 & 2.6 & NEP - Brayton pt., (BPM 50802-4) from STI \\
\hline FA11 & 2. & $\begin{array}{l}\text { NEP - Brayton pt., (BPP 50612-262, T11) from STI, } \\
\text { CPI }=0.45\end{array}$ \\
\hline FA12 & 2.3 & NEP - Brayton pt., (BPP 50610-258, T23) from STI \\
\hline FA13 & 3. & $\begin{array}{l}\text { NEP - Brayton pt., (BPP 50612-261, T34), same as FA8, } \\
\text { from STI }\end{array}$ \\
\hline FA16 & 1.5 & Helsinki (50703-136, E1), very bad ash, from STI, CPI=2.1 \\
\hline FA1 & 3. & NEP - Brayton pt., Unit \#3, ash with 5\% Gas co-firing \\
\hline FA20 & 2.0 & $\begin{array}{l}\text { NEP - Brayton pt., white-gray ash, problem ash, from STI, } \\
\text { CPI }=0.24\end{array}$ \\
\hline FA21 & 6.1 & NEP - Brayton pt. \\
\hline FA2 & & NEP - Salem Harbor ash, unprocessed, Surface area $=18 \mathrm{~m} 2 / \mathrm{g}$ \\
\hline FA2 & 65.5 & NEP - Salem Harbor ash, processed, Surface area $=36 \mathrm{~m} 2 / \mathrm{g}$ \\
\hline FA24 & 2.7 & $\begin{array}{l}\text { AEP-Columbus, Silo \#2, Unit \#1, from Eastern Bituminous, } \\
\text { good ash }\end{array}$ \\
\hline FA25 & 2.5 & AEP-Columbus, Silo \#4, Unit \#2, same as FA24 \\
\hline FA26 & 4 & AEP- Columbus Mountaineer Plant, Silo \#2, problem ash \\
\hline FA27 & 0.2 & $\begin{array}{l}\text { AEP, Rockport Plant (R.\#2) Regular ash from Powder River } \\
\text { Basin Coal, good ash }\end{array}$ \\
\hline FA28 & 2.4 & $\begin{array}{l}\text { same as Fa27, except produced from a feed stream containing } \\
5 \% \text { Petroleum Coke }\end{array}$ \\
\hline FA29 & 1.5 & AEP, Clinch River Plant, Virginia Coal, $3 \% \mathrm{CaO}$ but Class $\mathrm{F}$ \\
\hline & & NEP - Brayton pt., High Carbon Fly Ash \\
\hline FA & & NEP - Brayton pt., Low Carbon Fly Ash \\
\hline & & HEL 60520 B-3-E-2, from STI \\
\hline FA & & HEL 60517 B-6-E-2, from STI \\
\hline FA3 & 4.9 & BP 51103 B3 Feed, from STI \\
\hline FA35 & 17.5 & Petroleum Coke-western coal blended fuel \\
\hline FA36 & 0.3 & $\begin{array}{l}\text { "NA" Salt River Project, Navajo Station, Page Arizona, Subbit. } \\
\text { Coal from Black Mesa mine, Az, class F ash }\end{array}$ \\
\hline FA37 & 4.9 & $\begin{array}{l}\text { "CH" Public service of Colorado, Cherokke Station, either } \\
\text { Subbit. or Bit., class F ash }\end{array}$ \\
\hline FA38 & 0.2 & $\begin{array}{l}\text { "PAW" Public service of Colorado, Powder River Basin, class } \\
\text { C ash }\end{array}$ \\
\hline
\end{tabular}


Table 1 (Continued)

$\begin{array}{lll}\text { Sample } & \text { LOI } & \text { Remarks } \\ \text { No. } & (\text { mass } \%)\end{array}$

FA40 $\quad 1.1 \quad$ Welsh Power Plant, North-Easth Texas, 245620, class C

FA41 $\quad 1.1 \quad$ Welsh Power Plant, Texas, 245713, class C Fly Ash

FA42 $\quad 0.6 \quad$ Welsh Power Plant, Texas, 245716, class C Fly Ash

FA43 $\quad 0.6 \quad$ Flint Creek Plant, Arkansas, 213483, class C Fly Ash

FA44 $\quad 0.6 \quad$ Flint Creek Plant, Arkansas, 213491, class C Fly Ash

FA45 $\quad 0.7 \quad$ Flint Creek Plant, Arkansas, 22497, class C Fly Ash

Note: Reference to companies is only as to source of samples. The samples may not be typical of normal operations. CPI refers to Carbon Particle (Gao) Index. 
mineral components can cause discrepancies between the LOI values and true carbon content $^{10}$.

Table 1 shows that a broad range of samples has been assembled, exhibiting a wide range of LOI values. It should be noted that some samples are not necessarily typical of current utility practice. There is a sample (e.g., FA8) that has been deliberately enriched in carbon content by an electrostatic separations process developed for New England Power by Separations Technology, Incorporated (STI) of Needham, Massachusetts. There are likewise samples that have been prepared in situations in which petroleum coke has been co-fired with coal (FA28 and FA 35).

Work has begun on characterization of the ash samples with respect to porosity. This porosity exists mainly in the carbon phase, and is important because of the large amount of surface area that this porosity contains; it is this surface that is responsible for AEA adsorption, and which could be useful in other desirable adsorption applications. The actual results will be given in the next report, except for a few initial results to be presented in the next section. The principal technique to be employed is gas adsorption, using nitrogen and carbon dioxide. Full isotherms are being measured at $77 \mathrm{~K}$ and $195 \mathrm{~K}$, for $\mathrm{N}_{2}$ and $\mathrm{CO}_{2}$, respectively. In addition to the usual BET and Dubinin-Radushkevich surface areas available from these measurements, the isotherms will also be used to estimate micropore size distributions. These data will be later supplemented by data on meso- and macropore size distributions, to be obtained using mercury porosimetry.

\section{Characterization of the nature of the carbon surface}

It has been noted that the nature of a carbon surface can determine its efficacy in adsorbing AEAs. Oxidized surfaces did not appear to adsorb as much AEA as did unoxidized surfaces ${ }^{4}$. This is not surprising, since AEAs are essentially saponified resins and detergent-like surfactants, containing polar endgroups and quite likely long non-polar 
chains. The non-polar parts of the AEAs are critical to stabilizing the bubbles in the otherwise polar medium of the concrete mix; these parts of the AEA molecules gather at the air-water interface. The inorganic ash components, cement, and water are all polar, while only the carbon surfaces, and in particular, unoxidized carbon surfaces, are non-polar. The greater the amounts of non-polar carbon surface, the more effectively adsorption of the AEA by carbon will compete with the intended role of stabilizing bubbles.

It was decided that this hypothesized role of non-polar carbon surface could be tested by examining the surface of two otherwise quite similar fly ashes, FA5 and FA6. The former was produced at the Brayton Point Power Station of New England Power prior to low- $\mathrm{NO}_{\mathrm{X}}$ retrofit, while the latter was produced post-retrofit. Both are class $\mathrm{F}$ ashes from bituminous coal. There is a small but significant difference in LOI (FA5 gave 1.8\%, whereas FA6 gave 3.3\%, see Table 2). Surprisingly, the former sample proved to be quite acceptable in concrete applications, whereas the latter was entirely unacceptable. This led to an investigation of the differences between the samples.

There was a very large difference in Foam Index between the two samples. The results are shown in Table 2 (and the details of the test are given in Appendix B). The unacceptable sample, FA6 had an index which was an order of magnitude higher than the acceptable sample FA5. Clearly in this case, neither the dramatic increase in Foam Index, nor the related strongly unacceptable decline in actual concrete performance was predictable from the less than factor of two increase in carbon content, as suggested by LOI. Since the Foam Index test is fundamentally a test of adsorption, the search for an explanation of the differences centered on a more complete characterization of the surface. Two possibilities existed. One was that the carbon that remained in FA6 was of a higher surface area per unit mass than the carbon in FA5. The second possibility relates to the discussion concerning the nature of the surfactant AEAs; there may be a difference in adsorption of the AEAs based on surface polarity of the carbons in FA5 and FA6. 
The surface areas were measured using standard BET techniques. The results are given in Table 2. Once again, the difference in total surface areas of the ashes was not

\begin{tabular}{|c|c|c|c|c|}
\hline$\underline{\text { Sample }}$ & $\mathrm{LOI}(\%)$ & $\underline{\mathrm{N}} 2$-BET $\left(\mathrm{m}^{2} / \mathrm{g} \text { ash }\right)^{*}$ & $\underline{\mathrm{CO}}_{2}-\mathrm{DR}\left(\mathrm{m}^{2} / \mathrm{g} \text { ash }\right)^{\circ}$ & Foam Index \\
\hline FA5 & 1.8 & 1.9 & ND & 0.20 \\
\hline FA5- inorganic & - & 0.8 & ND & - \\
\hline FA5- carbon & - & $1.1(61)$ & ND & - \\
\hline FA6 & 3.3 & 2.7 & 3.4 & 0.249 \\
\hline FA6 - inorganic & - & 0.7 & ND & - \\
\hline FA6 - carbon & - & $2.0(61)$ & ND & - \\
\hline
\end{tabular}

sufficient to explain the enormous differences in behavior of the ashes in AEA Foam Index testing. The fair comparison between $\mathrm{N}_{2}$ and $\mathrm{CO}_{2}$ surface areas offered evidence that the characterization of surface area was not influenced by the low temperature diffusional limitation problems which sometimes lead to difficulties in interpretation of isotherms of microporous materials. The difference in nitrogen and carbon dioxide surface areas determined for FA6 has as much to do with the model used to calculate the areas from the isotherms as with differences in sorption capacities for the two gases.

Samples of the same fly ashes were then oxidized in air at high temperatures $\left(>725^{\circ} \mathrm{C}\right)$, to constant mass, in order to burn off the residual carbon. The surface areas of the remaining inorganic fractions were measured, and the results are shown in Table 2. It is seen that the remaining inorganic fly ash particles are largely non-porous and make a small contribution to the total surface area of the whole fly ash. This is consistent with their glassy, smooth spherical appearance as observed under the microscope. Thus even though the carbon is present in quantities of a few percent in the original fly ash samples, a majority of the fly ash surface area is located in that carbon. 
By subtraction of the surface area contributions of the inorganic fractions from the total surface areas, the surface areas of the carbons can be estimated. The results are again shown in Table 2. It may be seen that once again, the carbon surface areas differ by less than a factor of two, and that this does not offer an explanation for the much greater difference in Foam Index results. If the total surface areas offered by the carbons are divided by the fractions of carbon in the samples, the values shown in parentheses result. These are the surface areas per unit mass of carbon. The similarity of the surface areas per unit mass of carbon is striking; both give approximately $61 \mathrm{~m}^{2} / \mathrm{g}$, a typical value for bituminous coal chars. This reinforces the notion that differences in carbon porosity are not the basis for the major differences in AEA adsorption behavior.

This led to a search for methods to characterize more subtle differences in the surface chemistry of the unburned carbon fractions. Attention was turned to characterizing the surfaces in terms of polarity. For this purpose, adsorption calorimetry tests were performed with alcohols, using a flow microcalorimetry system. The details of these procedures are given in Appendix C. Briefly, these experiments involve placing a dry sample of fly ash into a calorimeter cell, and initially wetting it with a flow of pure nheptane. The n-heptane does not adsorb strongly to polar sites. A solution of an alcohol in n-heptane is then introduced into the cell, and the heat effect measured as the polar hydroxyl group in the alcohol interacts strongly with the polar surfaces on the material to be examined. The concentration of the alcohol is increased until no further heat effect is obtained, at which point the polar surface is assumed to have been saturated.

For certain adsorbates, relationships have been developed between the sorption enthalpy and the extent of the polar (or non-polar) surface in the carbon sample under study 7,11 . We have examined some alcohols for which such a relationship has not yet been reported. We have assumed that the proportionality constant for t-butanol is the same as that reported earlier for n-butanol ${ }^{7}$, which was $6.7 \mathrm{~m}^{2} / \mathrm{J}$. In light of some of the results to be given below, we believe that this is reasonable. We have also tested methanol, which 
has been reported by van Krevelen 12 to involve a heat of wetting of approximately 2.39 $\mathrm{m}^{2} / \mathrm{J}$.

Table 3 reports the results of the calorimetry experiments performed on samples FA5 and FA6, as well as on a third sample, FA23. The sample FA23 has been chosen for comparison because it is a carbon-enriched sample, produced by the STI separations process from what was a very high LOI sample to begin with. The surface area of FA23 is approximately $52 \mathrm{~m}^{2} / \mathrm{g}$ carbon, which is not very different from the $61 \mathrm{~m}^{2} / \mathrm{g}$ carbon determined earlier for FA5 and FA6 (see Table 2). Thus it is felt that FA23 has some similarity to the other two samples, even if there is much more carbon present.

Table 3. Total and Polar Surface Areas of Fly Ashes.

\begin{tabular}{|l|l|l|l|}
\hline Sample & FA5 & FA6 & FA23 \\
\hline \hline \% LOI & 1.8 & 3.3 & \\
\hline $\begin{array}{l}\text { Surface Area } \\
\left(\mathbf{m}^{2} / \mathbf{g}\right)\end{array}$ & & & \\
\hline $\mathrm{N}_{2}$-BET, whole ash & 1.9 & 2.7 & 34.9 \\
\hline carbon only & 1.1 & 2.0 & 33.7 \\
\hline n-butanol & 1.1 & 1.1 & 6.9 \\
\hline t-butanol & 1.0 & 0.9 & 4.0 \\
\hline methanol & 1.2 & 1.3 & ND \\
\hline
\end{tabular}

The values of the surface areas from the alcohol adsorption experiments are reported on the basis of the carbon contribution alone (the small contribution of the heat of sorption on the inorganic components has been subtracted). It is immediately apparent in comparing the various surface area values for FA5, that the surface is highly polar in character. Virtually $100 \%$ of the surface is accounted for by the polar adsorption methods. By way of contrast, in the case of the FA6 sample much of the surface shows itself to have a non-polar character (about 50\%). The FA23 sample has an even lower fraction of nonpolar surface. 
While these results do not in themselves constitute proof that it is the non-polar surface that is responsible for the high adsorption of AEA by sample FA6, it is clear that the explanation is consistent with the observation. Further to this point, the FA23 sample has a Foam Index of 4.097, which is a factor of 16.5 greater than the value for FA6, and more than 200 times greater than the value for FA5. Once again, these large differences cannot be predicted on the basis of total surface areas, but an explanation based upon AEA adsorption on non-polar area appears more reasonable. The non-polar area of FA23 is a factor of 30 higher than the value of non-polar area in FA6, if the non-polar area in these samples is calculated based upon the difference between the total and t-butanol areas. The fact that the Foam Index result does not scale better with non-polar area could be attributable to accessibility limitations in the FA23 sample. Note that this sample shows a larger difference between the n-butanol and t-butanol results than do the other samples. This suggests considering further the possible role of accessibility limitations in fly ash carbons.

\section{Studies on Accessibility of the Fly Ash Carbons}

Surface area alone may not be a sufficient indicator of the ability to adsorb a given species, if that surface area is located in pores which are very difficult to access because of their small size. This issue was examined in the context of the work performed with the alcohol sorbates and presented in Table 3. It would be expected that if molecular accessibility is an issue, then the smallest adsorbate, methanol, should give the highest apparent surface area, followed by the linear n-butanol and then the t-butanol, which contains the very bulky tertiary butyl group. Such a trend is indeed observed in comparing the values for the samples of Table 3, though, again, the choices of proportionality constants for the methanol and t-butanol could be challenged and this could influence the comparison. The fact that the values for methanol and t-butanol are as close as they are in FA5 and FA6 suggests that the porosity may not be overly restrictive to diffusion of large 
organics. To the extent that AEA molecules are likely to be characterized by dimensions not very much larger than t-butyl groups except perhaps in one co-ordinate direction, the implication is that diffusional restrictions are not responsible for the large differences in AEA adsorption (Foam Index) observed between FA5 and FA6.

The microcalorimetric determinations of surface area provided one further characterization of the porosity. It was observed that the timescale for the adsorption heat release was of order tens of minutes. This provides an estimate of the maximum timescale for diffusional transport of the alcohols into the pores, but cannot be used to infer a minimum because the existence of other limiting processes cannot be ruled out. A better way of examining the timescales of diffusional transport is to immerse the fly ash in a wellmixed bath of solution containing the adsorbate of interest. In this way, all external transport limitations could be ruled out. Such experiments were conducted with fly ash samples derived from FA23. The approach involved following actual AEA adsorption on the ash by tracking the change in UV absorbance (at $233 \mathrm{~nm}$ ) in an aqueous bath of AEA $^{13}$. The AEA tested in this case was Darex II ${ }^{\mathrm{TM}}$ from W.R. Grace \& Co. It was used in 10 vol. \% solution. It should be noted that by selecting one particular wavelength in the $\mathrm{UV}$, there may be a biasing towards a particular class of compounds in the AEA mixture, and that this could influence the measurement of timescales somewhat.

The diffusion rate experiments were conducted with different size fractions of the fly ash, in order to ascertain whether the limitation to transport exists on the particle size scale or on a scale defined by the porosity of the particles. Two different size fractions were prepared. One was $150-212 \mu \mathrm{m}$ and the other $38-45 \mu \mathrm{m}$. Figure 1 summarizes the results. The results are given in terms of the fraction of AEA which is adsorbed from the bath. Experiments were not continued up to the point of final equilibrium.

It is seen from Figure 1 that the timescale for uptake of the UV-active component of the AEA in the carbon-containing samples is of order hours, and that there appears to be little difference in rates between the larger and smaller particles (though the ultimate uptake 
is lower for the smaller particles). The intensity of stirring made no significant difference in the results, and thus the diffusional limitation exists within the particles. Figure 1 also

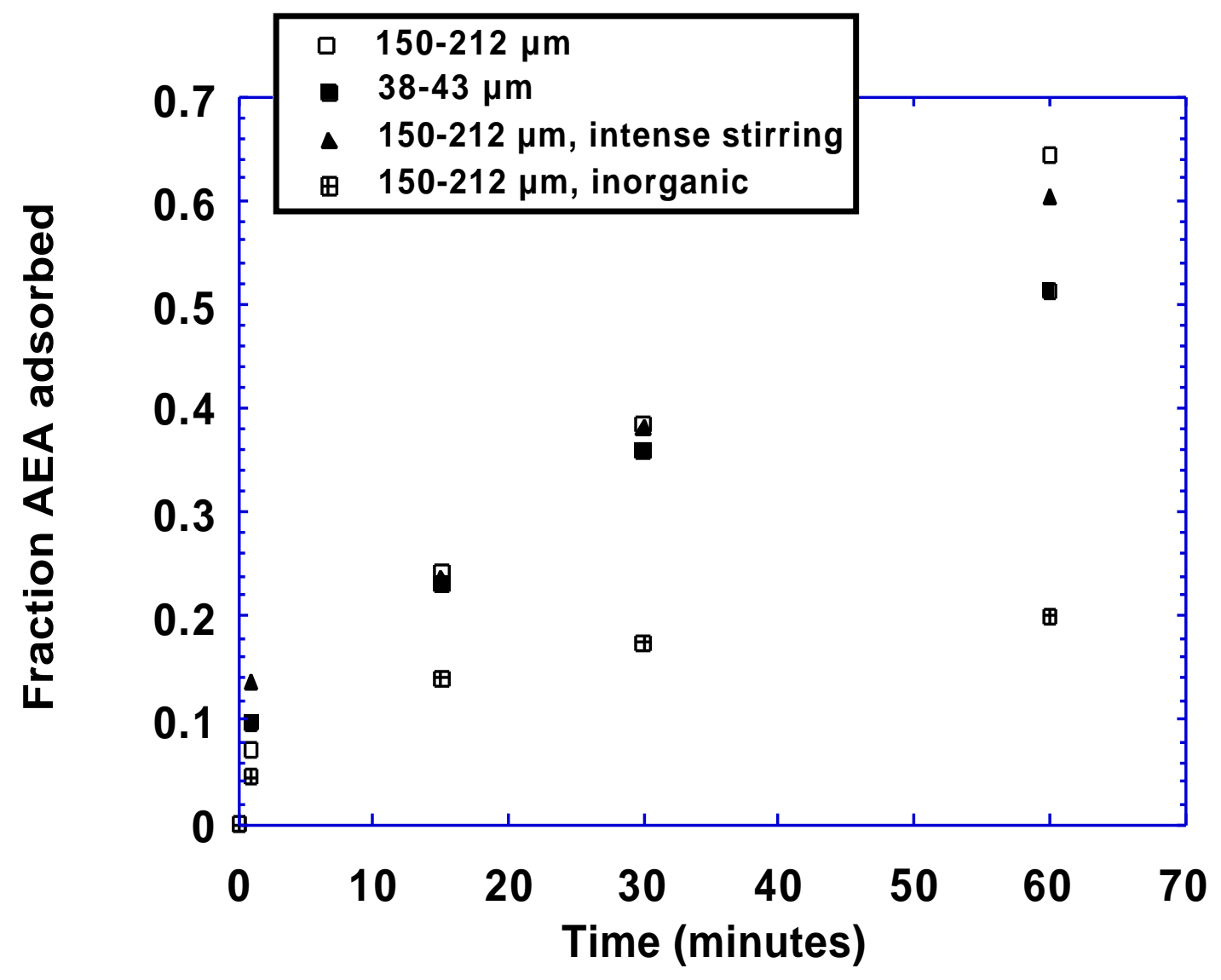

Figure 1. Adsorption dynamics of AEA on fly ash samples.

shows results for the inorganic fraction of the 150-212 $\mu \mathrm{m}$ ash, obtained by burning off the carbon in air at high temperature. There is some adsorption of the AEA onto this inorganic fraction, but it is seen that saturation is achieved rather quickly, and therefore the inorganic components should not play a role in determining the timescale for diffusion into the carbon fractions.

The absence of a difference in the diffusional timescales for the different particle sizes implies that the main locus of mass transfer resistance is within the particles. This is consistent with the microscopic images of the particles showing existence of numerous macropores in the carbon. These serve to feed the meso- and micro-pores, and the relevant 
diffusional length scale is presumably defined by the spacing between these large feeder pores. This spacing is naturally unaffected by the variation of particle size on a scale which is at least an order of magnitude larger.

It is not surprising that the AEA components should diffuse into fly ash FA23 more slowly than the alcohols examined above. These AEAs are mixtures of large organic resins, which would be expected to exhibit slower diffusional kinetics than the small alcohols. It should also be recalled that sample FA23 did indicate a difference in accessibility for nbutanol and t-butanol, implying pores that could prevent the access of larger organic species.

The practical implication of such long diffusion times is that if a sample containing this kind of porosity is encountered in practice, it might provide an acceptable "Foam Index" result on the normal timescale of that test, but then later fail due to adsorptive loss of AEA at longer times. There are anecdotal reports of such behavior from the field.

\subsection{CONCLUSIONS}

The project is in its initial phases, and much of the early work has been directed at establishing a useful and reliable sample bank. This part of the project is largely complete, though it is anticipated that interesting samples will be added throughout the project. The battery of tests that will be routinely performed on all samples has been defined and this work is well under way.

During this period, many of the experiments performed were dictated by the importance of understanding the behavior of fly ashes in concrete systems. The key role that carbon surface area can play had been earlier identified, but did not yet provide adequate explanation as to why certain post-retrofit (low $\mathrm{NO}_{\mathrm{X}}$ burner) ashes performed unusually poorly. The work performed to date has supported the hypothesis that beyond surface area, the chemical nature of the carbon surface (polarity) plays an important role in 
this regard. It was also noted that pore accessibility issues can play a role in shaping the interpretation of results of standard assays such as the Foam Index test. These conclusions await testing on a broader range of samples, and this will take place during the next reporting period.

The work done to date has put in place much of the basic framework necessary for characterizing the surface of the fly ash for other types of adsorbent applications. It is anticipated that during the next reporting period, there will be a large effort at expanding the range of adsorption testing to be performed. 


\subsection{REFERENCES}

1. Tyson, S. and Blackstock, T., Proc. Unburned Carbonaceous Material on Utility Fly Ash Conference, page 30, U.S. Dept. of Energy, April, 1995.

2. Fitzgerald, H., Chumley, J. and Waldrop, R., Proc. Unburned Carbonaceous Material on Utility Fly Ash Conference, p. 2, U.S. Dept. of Energy, April, 1995.

3. Hemmings, R.T., Venta, G.J., Golden, D.M., Proc. Unburned Carbonaceous Material on Utility Fly Ash Conference, p. 15, U.S. Dept. of Energy, April, 1995.

4. Gao, Y.-M., Shim, H.-S., Hurt, R.H., Suuberg, E.M. and Yang, N.Y.C., Energy and Fuels, 11, 457, 1997.

5. Freeman, E., Gao, Y.-M., Hurt, R.H., and Suuberg, E.M., Fuel, in press.

6. Helmuth, R. Fly Ash in Cement and Concrete, Portland Cement Association, 1987.

7. Groszek, A., Carbon, 25, 717 (1987).

8. Greenbank, M., Matviya, T., Tramposch, W., Proc. 21st Conf. Carbon, p. 369, Am. Carbon Society, 1993.

9. Randtke, S., Snoeyink, V., J. Am. Water Works Assoc., 75, 408 (1983).

10. Brown, R.C. and Dykstra, J., Fuel, 74, 570 (1995).

11. Groszek, A., Carbon, 27, 33 (1989).

12. van Krevelen, D.W., Coal, Chapter VII, Elsevier, Amsterdam, 1961.

13. Sabanegh, N. S., Sc.B. Thesis, Division of Engineering, Brown University, April, 1997. 


\section{Appendix A. LOI test procedures}

Loss-on-ignition tests were performed as follows. Fly ash samples were placed into small preweighed porcelain crucibles and then reweighed on a microbalance. Then the samples, in the uncovered crucibles, were placed into a laboratory oven at $130^{\circ} \mathrm{C}$ to dry for two hours. After drying the samples were covered and placed into a dessicator for cooling down up to room temperature. The samples were then reweighed and placed in an air ventilated laboratory oven at $740^{\circ} \mathrm{C}$ for two hours, after which the samples were again cooled down in the dessicator and reweighed. The change in weight between heating at $130^{\circ} \mathrm{C}$ and $740^{\circ} \mathrm{C}$ was the reported LOI, and is assumed to be the weight of unburned carbon in the original sample. Each fly ash was analyzed at least twice and an average percentage weight loss was calculated. The typical variance in LOI was quite small, and only in some cases did it get as high as 5\%, especially in ashes with LOIs higher than $0.5 \%$. For fly ashes which have smaller LOIs a higher variance was noted, and therefore these samples were analyzed further. Most of these low LOI ashes were also analyzed in a Thermogravimetric Apparatus (TGA). The results of the TGA analyses were generally in good agreement with those achieved in laboratory oven. The lowest LOI samples did not, however, give very distinct endpoints even in the TGA. 


\section{Appendix B. Foam index test procedure}

The foam index tests were performed as follows. Two grams of fly ash and 8 grams of Portland cement were placed in a $70 \mathrm{ml}$ cylindrical jar with a $40 \mathrm{~mm}$ I.D., $80 \mathrm{~mm}$ length. After that, $25 \mathrm{ml}$ of distilled water was added. The jar was then capped and thoroughly shaken for one minute to completely wet the cement and fly ash. A 10 vol-\% aqueous solution of Darex II $^{\mathrm{TM}}$ was added one drop at time from pipette gun with a $0.75 \mathrm{ml}$ tube. The size of the drop was adjustable, and this was done on the basis of the expected value of the Foam Index. After each addition the jar was capped and shaken approximately 15 seconds, after which the lid was removed and liquid surface was observed. Before the endpoint of the test the foam on the liquid surface is unstable. The endpoint was taken to occur when a constant foam was established on the surface at least 45 seconds.

The entire procedure was repeated using 8 grams of cement and no fly ash. Subtraction of the two test results (the value for the sample with fly ash less the value for the sample without fly ash) gave the reported foam index for the fly ash, in ml.

Foam index tests were carried out twice for those samples which showed good agreement between the results; otherwise an additional test was performed and the final foam index was calculated as the average. 


\section{APPENDIX C. Microcalorimetry Equipment and Procedures}

\section{Equipment}

Experiments were performed using a Mark 3V Flow Microcalorimeter (FMC) manufactured by Microscal, Ltd. of London, U.K. The device consists of a sample cell of $0.20 \mathrm{ml}$ volume through which a fluid can be continuously passed. Thermistors located within the cell and surrounding PTFE polymer block allow the heat release from a sample in the cell to be determined. The sensed temperature difference is related to heat flow by calibration, using a precision resistor embedded in the sample cell, to which a precisely metered amount of energy can be delivered. The entire sample cell assembly is contained in an insulated, thermostatted housing, capable of operation up to $150^{\circ} \mathrm{C}$.

Liquid flow through the sample cell is controlled using Perfusor IV syringe pumps. Two pumps are connected to the sample cell inlet tube through a four way valve. This permits instantaneous switching from one liquid solution to another. The flowrates of the pumps are adjustable.

Data were logged automatically using an interfaced personal computer. The output is a voltage signal amplified into the $0-5$ volt range.

\section{Procedure}

Two solutions are prepared before the experiment is begun. One is normally a pure carrier solvent (in this case, heptane). The other is generally a dilute solution of the probe molecule (e.g., n-butanol) in heptane. It is typical to begin with a concentration which is around 0.1 vol. \% or less. This is increased stepwise until saturation has been achieved on the sample surface. The cell enclosure is also set to the desired temperature well in advance of an experiment. For these experiments, the temperatures were in the range from 25 to $31^{\circ} \mathrm{C}$. It was simply desired to maintain the temperature near ambient levels, but naturally it is difficult to control very precisely near room temperature in the face of significant long- 
term fluctuations in room temperature. The stability of the control system was however good in the short term.

Approximately $0.15 \mathrm{ml}$ of dry sample is introduced into the sample cell for an experiment. It is important to not overfill the sample cell, as any heat effects obtained outside of the cell will naturally not be properly recorded. Loading of the cell must be performed carefully. In this case, the outlet tube from the cell was left open, and 1 to $2 \mathrm{ml}$ of pure carrier fluid was initially passed through the cell in order to rinse it. The dry powder sample was then poured into the cell through a funnel. More carrier fluid was then passed through the cell in order to wash all particles into the sample cell body. After allowing the bed to settle for a few minutes, the sample cell connections were attached, and the carrier flow was begun. In the experiments reported here, the carrier flow was measured to be $6.75 \mathrm{ml} / \mathrm{hr}$.

Data recording was then begun, and the approach to a steady baseline was monitored. Once the stable baseline had been obtained, the switch was made to the probe solution, and the peak associated with the heat release was recorded. The adsorption events are inherently exothermic. As the data at one solution concentration is recorded, the syringe containing the pure carrier is switched to the next higher concentration, and the procedure repeated until an increase in concentration no longer gives an exothermic peak. At this point the surface is saturated with respect to the adsorbate. By switching back to a pure carrier flow, a desorption step occurs, and should involve an endothermic event of the same magnitude as the exotherm for adsorption. Calibration of the cell, with sample, is easily performed at various points throughout the experiment. The peaks which are obtained during adsorption, desorption, or calibration are numerically integrated to provide the net heat effect of the step. 